\title{
Assessment of Climate Change Impact on Water Resources of Lesser Zab, Kurdistan, Iraq Using SWAT Model
}

\author{
Nahlah Abbasa', Saleh A. Wasimia1, Nadhir Al-Ansari² \\ ${ }^{1}$ School of Engineering \& Technology, Central Queensland University, Melbourne, Australia \\ ${ }^{2}$ Geotechnical Engineering, Lulea University of Technology, Lulea, Sweden \\ Email: n.abbas@cqu.edu.au,s.wasimi@cqu.edu.au,nadhir.alansari@ltu.se
}

How to cite this paper: Abbasa, N., Wasimia, S.A. and Al-Ansari, N. (2016) Assessment of Climate Change Impact on Water Resources of Lesser Zab, Kurdistan, Iraq Using SWAT Model. Engineering, 8, 697715.

http://dx.doi.org/10.4236/eng.2016.810064

Received: September 27, 2016

Accepted: October 24, 2016

Published: October 27, 2016

Copyright (c) 2016 by authors and Scientific Research Publishing Inc. This work is licensed under the Creative Commons Attribution International License (CC BY 4.0).

http://creativecommons.org/licenses/by/4.0/

\section{Abstract}

Kurdistan in northern Iraq, a semi-arid region, predominantly a pastureland, is nourished by Lesser Zab, which is the second major tributary of Tigris River. The discharge in the tributary, in recent times, has been experiencing increasing variability contributing to more severe droughts and floods supposedly due to climate change. For a proper appreciation, SWAT model has been used to assess the impact of climate change on its hydrological components for a half-centennial lead time to 2046-2064 and a centennial lead time to 2080-2100. The suitability of the model was first evaluated, and then, outputs from six GCMs were incorporated to evaluate the impacts of climate change on water resources under three emission scenarios: A1B, $\mathrm{A} 2$ and $\mathrm{B} 1$. The results showed worsening water resources regime.

\section{Keywords}

Climate Change, Water Resources, Lesser Zab, SWAT Model

\section{Introduction}

There is mounting evidence that climate change would enhance extreme weather events such as tropical cyclones, floods, droughts and bushfires impacting on water resources of a region [1]. The impact on the hydrological cycle is mainly through the alteration of evapotranspiration and precipitation [2] [3]. These alterations often manifest as severe droughts and floods imparting greater variability in river discharge and soil moisture. [4] [5] have identified Iraq as highly vulnerable to climate change. The adverse effects on water resources could negatively impact the environment and the economy of the country, particularly the agricultural sector. There is a strong demand from the deci- 
sion makers for predictions about the potential impacts of climate change involving the duration and magnitude of precipitation, which has ramifications on sustaining and managing water resources appropriately to meet water scarcity that has become pronounced [6]. A tributary of Tigris River, Lesser Zab, is the backbone of water resources of Kurdistan region in northern Iraq. So far, water issues related to climate change in Lesser Zab catchment have not been well addressed within climate change analyses and climate policy construction [7]. This study aims to fill that void.

\section{Study Area}

Lesser Zab (also known as little or Lower Zab) originates from north-eastern Zagros Mountains in Iran and its watershed is located approximately between $35.160 \mathrm{~N}$ to $36.790 \mathrm{~N}$ latitudes and $43.390 \mathrm{E}$ to $46.260 \mathrm{E}$ longitudes. In the upstream of the basin, the river runs through deep valleys joined by a number of small streams such as the Banah and Qazlaga, and after a length of about $302 \mathrm{~km}$, the river joins the Tigris River at Fatah (south of Mosul). Lesser Zab drains an area of about 15,600 km², $80 \%$ of which is located in Iraq and the rest in Iran. Approximately $70 \%$ of the watershed is covered by pasture and the remaining $30 \%$ is used for agriculture. The dominant soil is Xerosols. Figure 1 provides the Digital Elevation Model (DEM) and landuse of the watershed.

The climate of the Lesser Zab basin is arid to semi-arid with wet winters and dry summers. The mean annual temperature varies from $10^{\circ} \mathrm{C}$ in the north to $22^{\circ} \mathrm{C}$ in the south. The mean annual rainfall ranges from $1500 \mathrm{~mm}$ in mountainous north to 350 $\mathrm{mm}$ in the flats of the south. The mean annual flow volume of Lesser Zab at Dukan is about 7.18 billion cubic meters, manifesting highly seasonal flow regime as shown in Figure 2 with peak flow occurring in early spring (April) primarily due to snowmelt. Two dams have been constructed within Iraqi part namely; Dukan and Dibis dams for agricultural usage, hydropower and flow regulation [8].
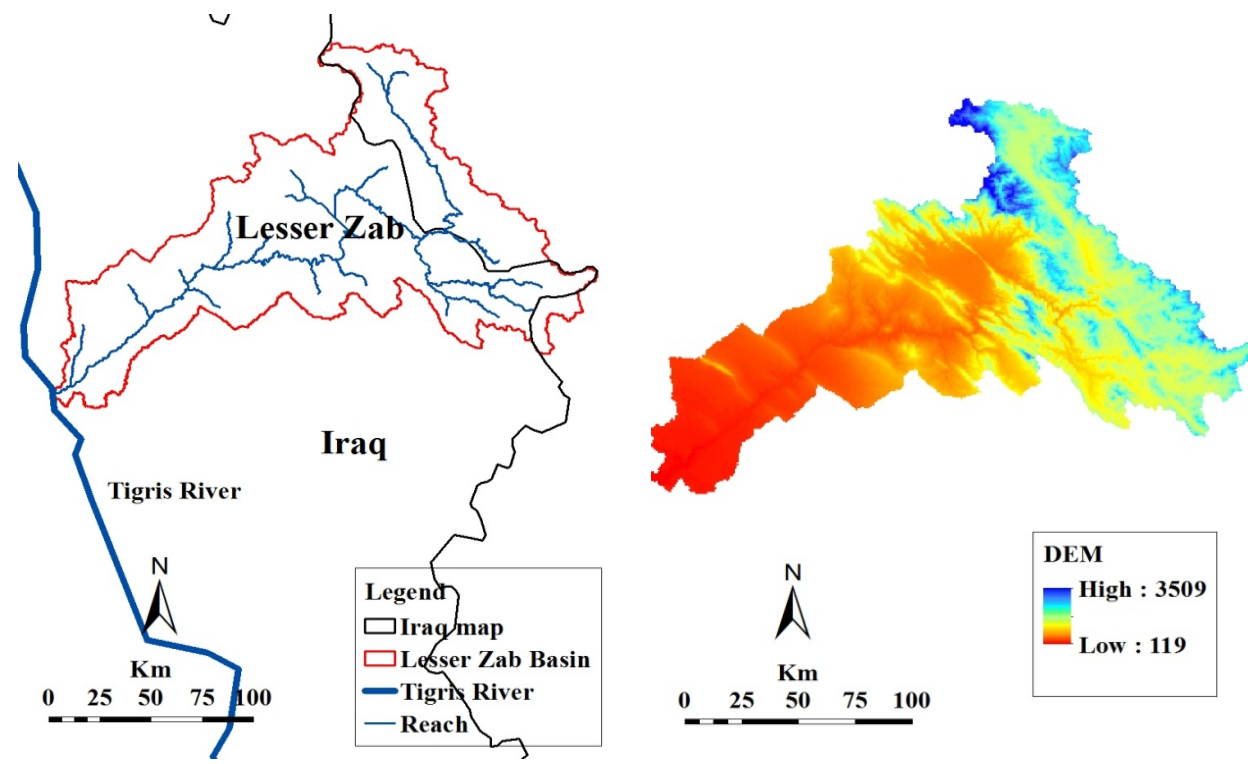

Figure 1. DEM and landuse map of Lesser Zab. 


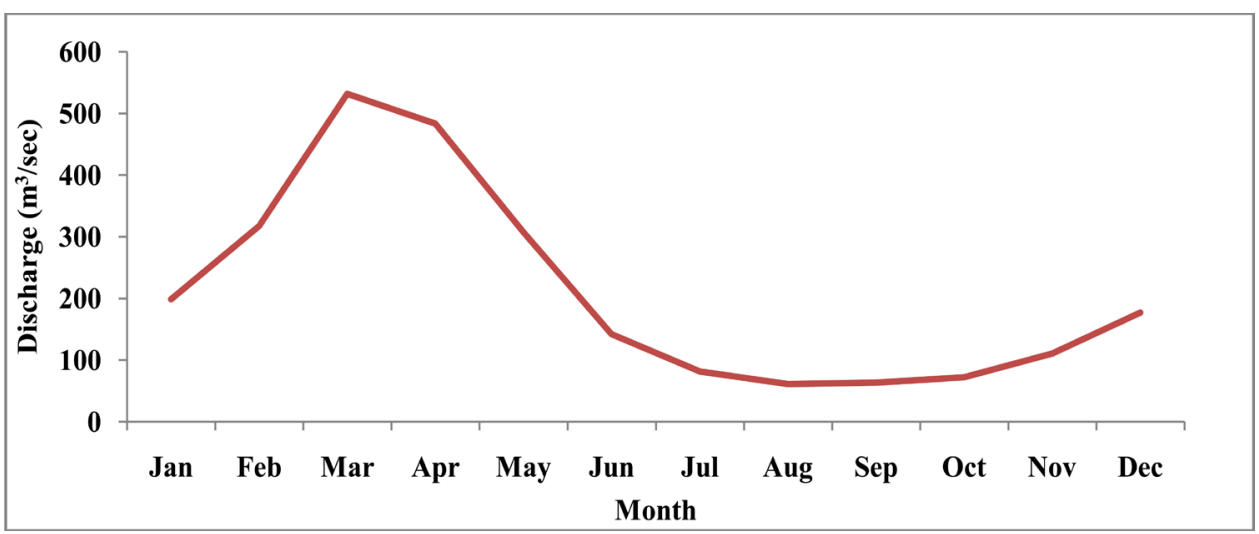

Figure 2. Average monthly streamflows of Lesser Zab at Dukan during 1979-2004.

\section{Description of SWAT Model}

The Soil and Water Assessment Tool (SWAT) model [9] is a river watershed scale, semi-distributed and physically based continuous time (daily computational time step) model for analysing hydrology and water quality at various watershed scales with varying soils, land use and management conditions on a long-term basis. The model was originally developed by the United States Department of Agriculture (USDA) and the Agricultural Research Service (ARS). SWAT system is embedded within a Geographic Information System (ArcGIS interface), in which different spatial environmental data, including climate, soil, land cover and topographic characteristics can be integrated.

Two major divisions, land phase and routing phase, are conducted to simulate the hydrology of a watershed. The land phase of the hydrological cycle predicts the hydrological components including surface runoff, evapotranspiration, groundwater, lateral flow, ponds, tributary channels and return flow. The routing phase of the hydrological cycles is the movement of water, sediments, nutrients and organic chemicals via the channel network of the basin to the outlet. The estimation of surface runoff is done through two methods; the SCS curve number procedure [9] and the Green and Ampt infiltration method [10]. The SCS method has been used in this study due to nonavailability of sub-daily data that is required by the Green and Ampt infiltration method. The model estimates the volume of lateral flow depending on the variation in conductivity, slope and soil water content. A kinematic storage model is utilized to predict lateral flow through each soil layer. Lateral flow occurs below the surface when the water rates in a layer exceed the field capacity after percolation.

The groundwater simulation is divided into two aquifers which are a shallow aquifer (unconfined) and a deep confined aquifer in each watershed. The shallow aquifer contributes to streamflow in the main channel of the watershed. Water that percolates into the confined aquifer is presumably contributing to stream flow outside the watershed. Three methods are provided by SWAT model to estimate potential evapotranspiration (PET) - the Penman-Monteith method [11] [12]. Water is routed through the channel network by applying either the variable storage routing or Muskingum river routing methods using the daily time step. 


\subsection{Model Input}

Enormous amount of input data is required by SWAT model to fulfil the tasks envisaged in this research. Basic data requirements for modelling included digital elevation model (DEM), land use map, soil map, weather data and discharge data. DEM was extracted from ASTER Global Digital Elevation Model (ASTERGDM) with a 30 meter grid and $1 \times 1$ degree tiles (http://asterweb.jpl.nasa.gov/GDEM.ASP). The land cover map was obtained from the European Environment Agency (http://www.eea.europa.eu/data-and-maps/data/global-land-cover-250m) with a 250 meter grid raster for the year 2000. The soil map was collected from the global soil map of the Food and Agriculture Organization of the United Nations [13]. Weather data included daily precipitation, 0.5 hourly precipitation, maximum and minimum temperatures obtained from the Iraq's Bureau of Meteorology. Monthly stream flow data was collected from the Iraqi Ministry of Water Resources/National Water Centre.

\subsection{Model Setup}

In SWAT model, the watershed is divided into sub-basins based on the digital elevation model (DEM). The land use map, soil map and slope datasets were embedded with the SWAT databases. Thereafter, sub-basins are further delineated by Hydrologic Response Units (HRUs). HRUs are defined as packages of land that have a unique slope, soil and land use area within the borders of the sub-basin. HRUs enable the user to identify the differences in hydrologic conditions such as evapotranspiration for varied soils and land uses. Routing of water and pollutants are predicted from the HRUs to the sub-basin level and then through the river system to the watershed outlet.

\subsection{Model Calibration and Evaluation}

To evaluate the performance of the SWAT model, the sequential uncertainty fitting algorithm application (SUFI-2) embedded in the SWAT-CUP package [14] was used. The advantages of SUFI-2 are that it combines optimization and uncertainty analysis, can handle a large number of parameters through Latin hypercube sampling and it is easy to apply. Furthermore, as compared with different techniques in connection to SWAT such as generalized likelihood uncertainty (GLU) estimation, parameter solution (parsol), Markov Chain Monte Carlo (MCMC), SUFI-2 algorithm was found to obtain good prediction uncertainty ranges with a few numbers of runs. This efficiency is of great significance when implementing complex and large-scale models.

The SUFI-2 first identifies the range for each parameter. After that, Latin Hypercube method is used to generate multiple combinations among the calibration parameters. Finally, the model runs with each combination and the obtained results are compared with observed data until the optimum objective function is achieved. Since the uncertainty in forcing inputs (e.g. temperature, rainfall), conceptual model and measured data are not avoidable in hydrological models, the SUFI-2 algorithm computes the uncertainty of the measurements, the conceptual model and the parameters by two measures: P-factor and R-factor. P-factor is the percentage of data covered by the $95 \%$ pre- 
diction uncertainty (PPU) which is quantified at $2.5 \%$ and $97.5 \%$ of the cumulative distribution of an output variable obtained through Latin Hypercube Sampling. The $\mathrm{R}$-factor is the average width of the 95 PPU divided by the standard deviation of the corresponding measured variable. In an ideal situation, P-factor tends towards 1 and R-factor to zero. Further, SUFI-2 calculates the Coefficient of Determination (R2) and the Nasch-Sutcliff efficiency (ENC) [15] to assess the goodness of fit between the measured and simulated data.

The ENC value is an indication of how well the plot of the observed against the simulated values fits the 1:1 line. It can range from negative infinity $(-\infty)$ to one. The closer the value to one, the better the prediction is. While the value of less than 0.5 indicates unsatisfactory model performance [16].

SUFI-2 enables users to conduct global sensitivity analysis, which is computed based on the Latin Hypercube and multiple regression analysis. The multiple regression equation is defined as below.

$$
g=\alpha+\sum_{i=1}^{m} \beta_{i} * b_{i}
$$

where: $g$ is the value of evaluation index for the model simulations, $\alpha$ is a constant in multiple linear regression equation, $\beta$ is a coefficient of the regression equation, $b$ is a parameter generated by the Latin hypercube method and $m$ is the number of parameters.

The $\mathrm{t}$-stat of this equation which indicates parameter sensitivity is applied to determine the relative significance for each parameter, the more the sensitive parameter, the greater is the absolute value of the t-stat. When p-value is used, it is an indication of the significance of the sensitivity, p-value close to zero has more significance.

\subsection{General Circulation Model (GCM) Inputs}

To study the long term expected climate change in the Lesser Zab basin CGCM3.1/T47, CNRM-CM3, GFDL-CM2.1, IPSLCM4, MIROC3.2 and MRI CGCM2.3.2 were selected for this purpose under a very high emission scenario (A2), a medium emission scenario (A1B) and a low emission scenario (B1) for two future periods (2046-2064) and (2080-2100). Then the data of the base line period (1982-2010) which includes temperatures and precipitation were used for comparison purposes with the resulting projected data to show the differences in water resources within the basin. BCSD method was used to downscale the GCM results [17].

\section{Results and Discussion}

\subsection{Sensitive Analysis}

Stream flow in SWAT model is expressed using 25 parameters. To use the model these parameters are to be undergoing sensitivity analysis and then ranked so that non-effective parameters can be disregarded. The results (Table 1) indicated that there are 12 most sensitive parameters. These parameters were then ranked (Table 1).

CN2 was the dominant SWAT calibration parameter for the Lesser Zab basin. In 
Table 1. Most sensitive parameters (ranked) related to stream flow in the Lesser Zab basin.

\begin{tabular}{cccc}
\hline Parameter & Rank & Initial values & Fitted values \\
\hline CN2 & 1 & $-0.2-0.2$ & 0.01 \\
ALPHA_BF & 2 & $0-1$ & 0.175 \\
SOL_AWC & 3 & $-0.2-0.4$ & 0.3625 \\
GW_DELAY & 4 & $30-450$ & 187.5 \\
SURLAG & 5 & $0.05-24$ & 17.4 \\
GW_REVAP & 6 & $0-0.2$ & 0.085 \\
HRU_SLP & 7 & $0-0.2$ & 0.2 \\
SFTMP & 8 & $-5-5$ & 4.25 \\
GWQMN & 9 & $0-2$ & 1.25 \\
CH_K2 & 10 & $5-130$ & 76.87 \\
ESCO.hru & 11 & $0-0.2$ & 0.005 \\
SLSUBBSN & 12 & $0-0.2$ & 0.15 \\
\hline
\end{tabular}

most SWAT applications in different watersheds CN2 was found to be the most sensitive parameter [18]. CN2 has major impact on the amount of runoff generated from HRUs, thus a relatively higher sensitivity index can be predicted for most of the basins. ALPHA-BF was ranked as the second. This result is consistent with the finding of [19], who found that ALPHA is highly sensitive groundwater parameter in SWAT calibration.

\subsection{Calibration and Validation}

The model was calibrated and validated at two discharge stations: Alunkubri and Dukan. Alunkubri station is located at $35.750 \mathrm{~N}$ and $44.130 \mathrm{E}$, in the upper basin. Dukan is at $35.880 \mathrm{~N}$ and $44.960 \mathrm{E}$, in the lower basin. The calibration period for Alunkubri was eight years (1977-1984) and the validation period was three years (1985-1987). At Dukan station, the model was calibrated for sixteen years (1977-1995) and validated for nine years (1996-2004). The first three years for Dukan was warm up period, but this could not be done for Alunkubri due to short period of record. The results of SWAT calibration and validation at Alulnkubri and Dukan stations are shown in Figure 3 and Figure 4, respectively. The results of calibration and validation of the SWAT model demonstrate that simulated data is in good agreement with measured data in both stations visually as well as based on $\mathrm{R}^{2}$ and ENC criteria. It is obvious that ENC and R2 for Dukan station (downstream station) are greater than those for Alunkubri (upstream station) because the model is calibrated from upstream to downstream. The calibrated parameters of upstream stations contribute partially to the calibration process of downstream stations thus improving simulation results of downstream stations. $\mathrm{R}^{2}$ and ENC for Dukan and Alunkubri were, respectively, 0.85 and 0.83 for calibration and 0.82 and 0.77 for validation. Dukan is the entire watershed outlet. Overall, the model performance is acceptable at monthly scale. 


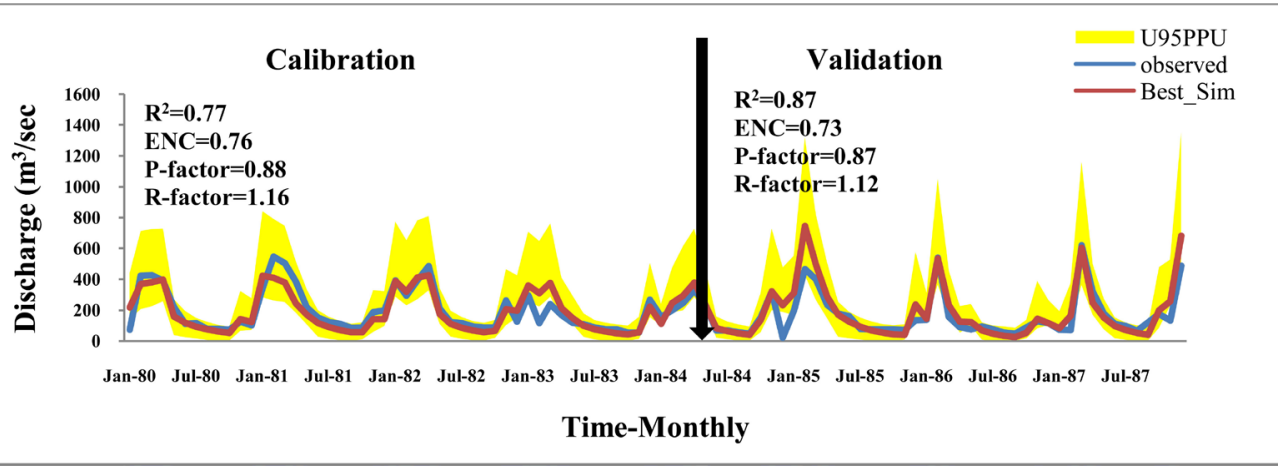

Figure 3. Calibration and validation of the SWAT model at monthly scale at Alunkubri station.

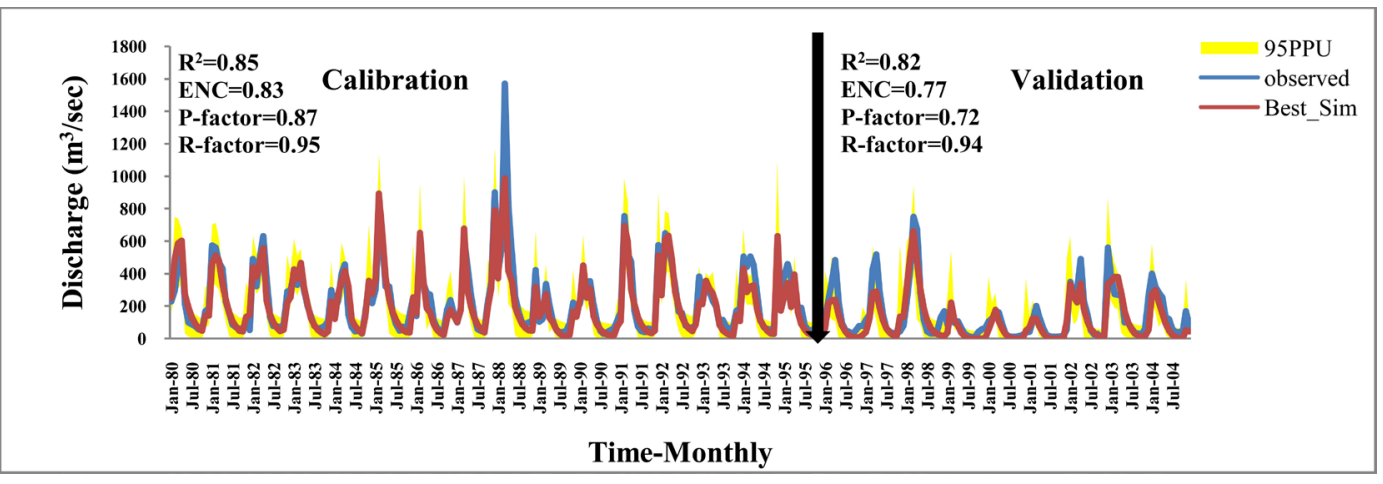

Figure 4. Calibration and validation of the SWAT model at monthly scale at Dukan station.

\subsection{Trends in Precipitation, Blue Water and Green Water in the Past}

Using the calibrated model, annual precipitation, blue water (summation of water yield and deep aquifer recharge) and green water including green water storage (soil water content) and green water flow (evapotranspiration) were estimated during the last three decades to identify the impacts of climate change on the water cycle components. Blue water is the freshwater humans can access for instream use or withdrawal. Green water does not provide direct access to humans but sustains natural flora and rain-fed agriculture. Figure 5 captures the spatial distribution of precipitation in HRUs over three consecutive decades. From the figure it is apparent that there is a general declining trend in precipitation over time.

Both the blue water and green water in the Lesser Zab basin decreased from upstream to downstream (Figure 6 and Figure 7). Generally, green water tracks blue water, where blue water flows are high, green water flows also have a tendency to be high. The spatial patterns of the blue and green water flows are largely affected by the spatial patterns of precipitation. In addition, land cover contributes to the shaping of spatial patterns. The average annual blue water and green water for the entire catchment significantly decreased from 1980s to 2000s. It is plausible that the decreasing trends in the average annual blue water and green water are attributable to climate change. Green water flow stayed nearly consistent due to hypothesis that land cover stay consistent through the period of 1980-2010 (Table 2). 

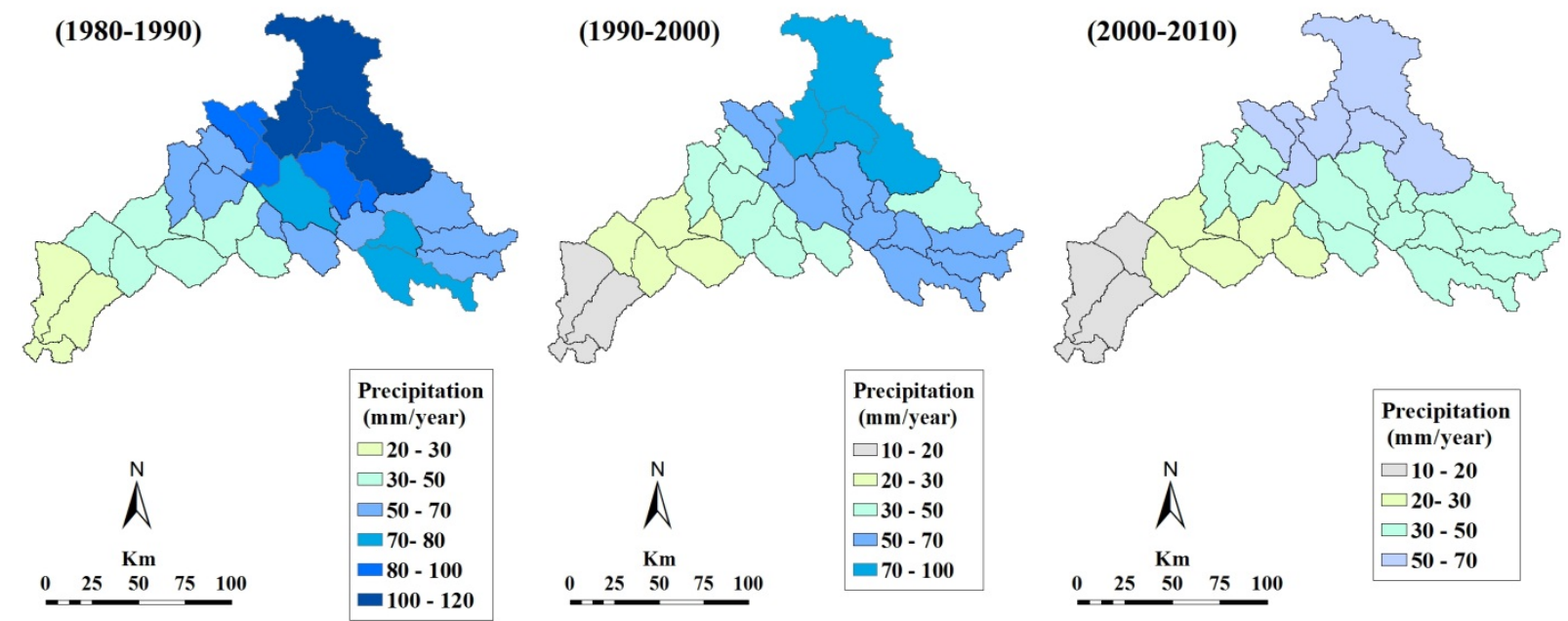

Figure 5. Spatial distribution of precipitation in the Lesser Zab basin over three consecutive decades.
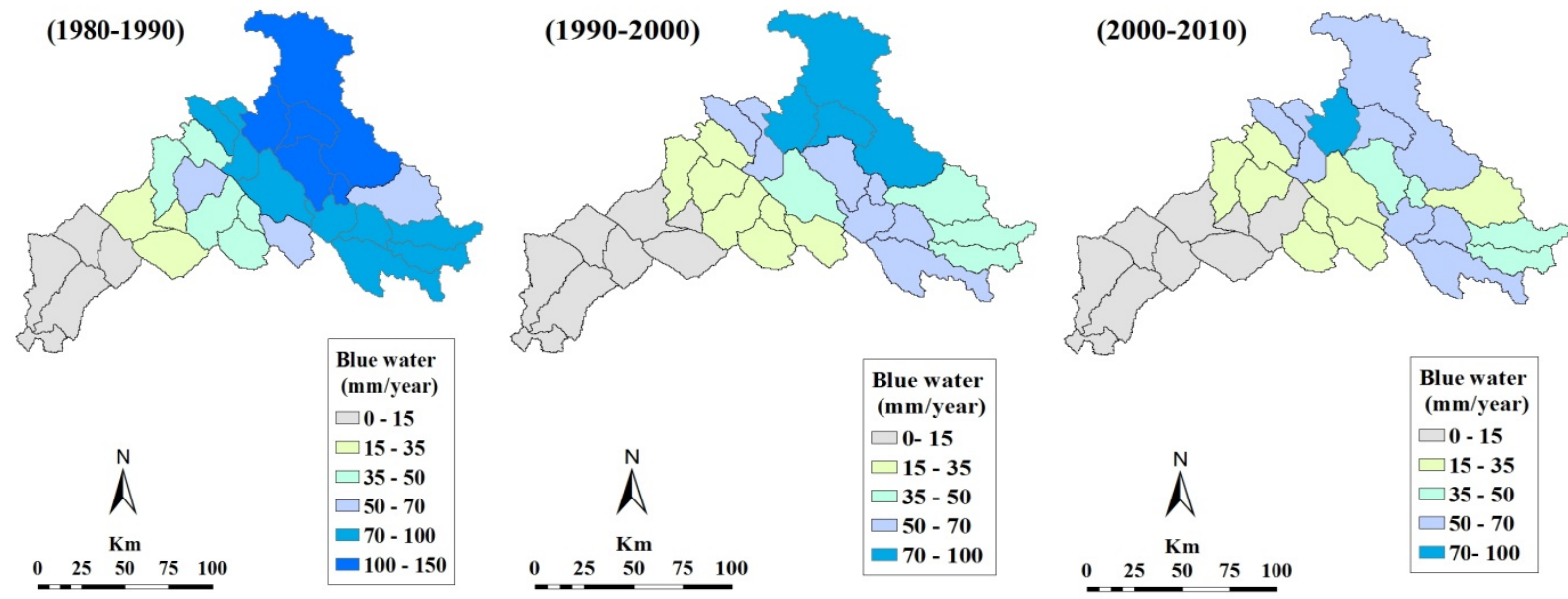

Figure 6. Spatial distribution of blue water in Lesser Zab basin for three consecutive decades.
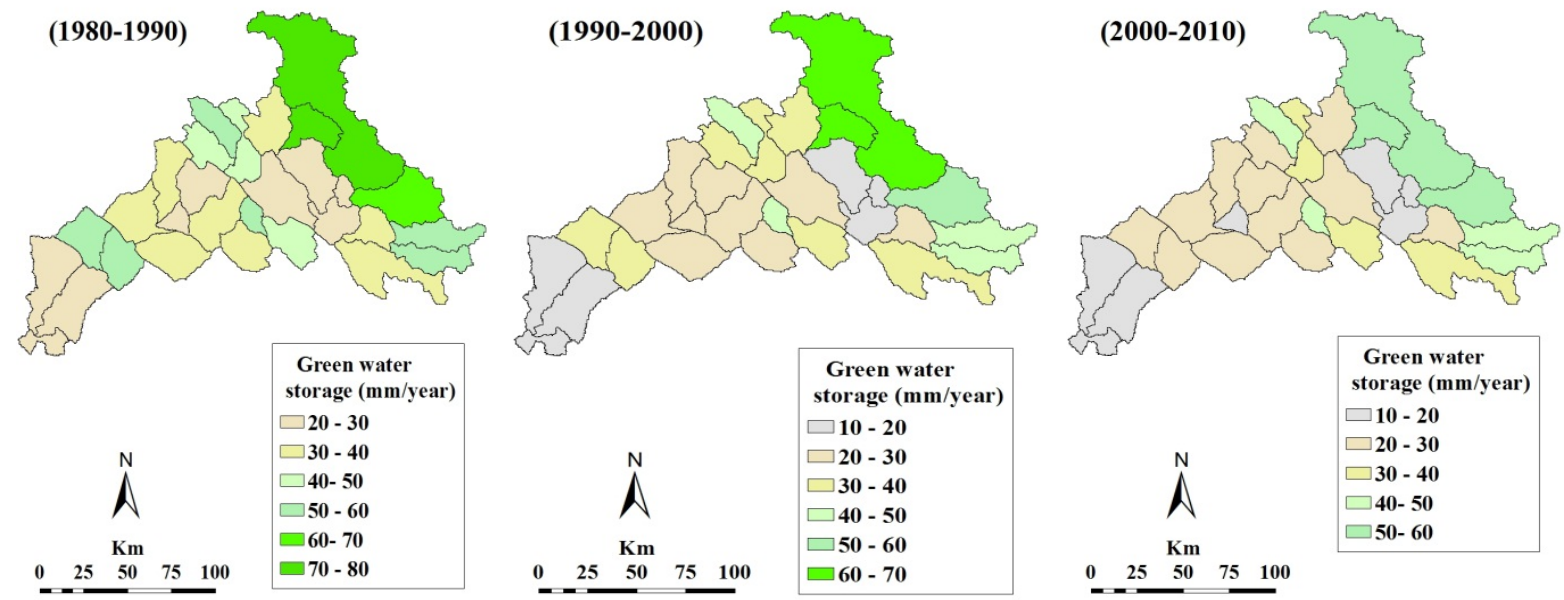

Figure 7. Spatial distribution of green water storage in Lesser Zab basin for three consecutive decades. 
Table 2. Relative changes in precipitation, blue water and green water in the Lesser Zab basin.

\begin{tabular}{cccc}
\hline \multicolumn{3}{c}{ Rate of relative change in the last three decades } \\
\hline Water component & 1990s vs 1980s & 2000s vs 1990s & 2000s vs 1980s \\
\hline Precipitation & -0.28 & -0.15 & -0.39 \\
Blue water & -0.32 & -0.27 & -0.34 \\
\hline Green water storage & -0.21 & -0.19 \\
\hline
\end{tabular}

Figure 8. Water scarcity in each modeled Lesser Zabsub basin represented by the modeled 1980 to 2010 annual average blue water flow availability per capita per year (using population of 2005) the average (Avg.) value of the 95PPU range.

\subsection{Blue Water Scarcity Indicators}

The calibrated model was also used for blue water scarcity analysis. The five water stress ranks introduced in Figure 8 follow the most widely applied water stress indicators defined by [20] [21]. The water stress threshold defined as $1700 \mathrm{~m}^{3} \cdot \mathrm{capita}^{-1} \cdot \mathrm{year}^{-1}$. The $1700 \mathrm{~m}^{3} \cdot$ capita $^{-1} \cdot \mathrm{year}^{-1}$ is calculated based on estimations of water needs in the household, agricultural, industrial and energy sectors, and the demand of the environment [22]. A value equal or greater than $1700 \mathrm{~m}^{3} \cdot$ capita $^{-1} \cdot \mathrm{year}^{-1}$ is considered as an adequate to meet water demands. When water supply drops below $1000 \mathrm{~m}^{3} \cdot \mathrm{capita}^{-1} \cdot \mathrm{year}^{-1}$ is referred as water scarcity. While a value below $500 \mathrm{~m}^{3} \cdot$ capita $^{-1} \cdot \mathrm{year}^{-1}$ is considered as extreme scarcity. The water availability per capita and water stress indicators were estimated for each of the $61 \mathrm{sub}$ basins of the Greater Zab catchment using the $2.5 \mathrm{arcmin}$ population map available from the Center for International Earth Science (CIESIN) Gridded Population of the World (GPW, version 3, http://sedac.ciesin.columbia.edu/gpw) for 2005. Figure 8 demonstrates the spatial distribution of water resources per capita per year during the period of 1980-2010 based on the population estimates of the year of 2005. In general, up to $68 \%$ of the basin area, 
located in the lower part of the basin, experiences extreme water scarcity. Twenty two percent of the basin experienced below $1000 \mathrm{~m}^{3} /$ capita.year. Ten percent only experiences sufficient water blue, located in the upper part of the basin.

\subsection{Uncertainty and Natural Variation in Green Water Storage}

For the rainfed crops, the average of the months per year for the period of 1980 to 2010 where green water storage is available (defined as $>1 \mathrm{~mm} \cdot \mathrm{m}^{-1}$ ) is of greatest significance [23]. This is shown in Figure 9(a). Up to 65\% of the basin experiences 6 to 8 months (October to May) in which green water is available. The standard deviation (SD) of the months per year without depleted soil water is presented for the 1980-2010 period in Figure 9(b). The areas with a high SD such as the lower part of the basin show high variability in green water storage availability. This could lead to reduced crop yield. For sustaining agriculture production in this part, adjusting irrigation systems and applying alternative cropping practices are highly recommended.

\subsection{The Impacts of Climate Change on Temperature and Precipitation under A2, A1B, B1 Emission Scenarios}

Mean annual temperature and precipitation outputs from the six GCMs identified earlier were processed for the Lesser Zab basin under three scenarios (A2, A1B, B1). Table 3 captures the projected changes in mean annual temperature for two future periods (2046-2064) and (2080-2100) relative to base period (1980-2010). Changes in mean temperature tend to be more consistent than precipitation. All the models showed consistent increasing trends in temperature.

Table 4 captures the projected relative changes in mean annual precipitation from the baseline scenario (1980-2010). Generally, all models showed a decrease in mean annual precipitation at half-centennial future (2046-2064) and centennial future

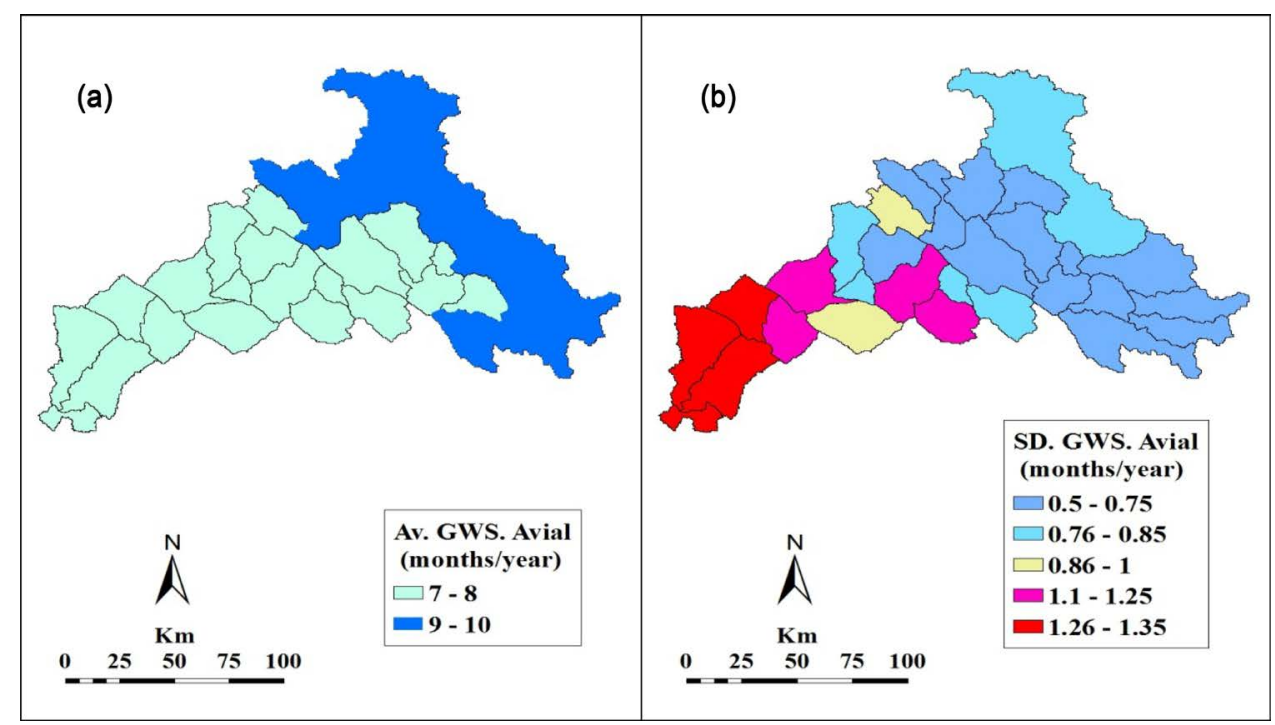

Figure 9. (a) The 1980-2010 average (Av.) and (b) standard deviation (SD) of the number of months per year where the green water storage $(\mathrm{GW}-\mathrm{S})$ is available for usage. 
Table 3. GCM predicted changes in the mean annual temperature of the future under A2, A1B and $\mathrm{B} 1$ scenarios.

\begin{tabular}{ccccccc}
\hline \multicolumn{5}{c}{ GCM names predicting changes in mean annual temperature $\left({ }^{\circ} \mathrm{C}\right)$} \\
\hline Period & CGCM3.1/T47 & CNRM-CM3 & GFDL-CM2.1 & PSLCM4 & MIROC3.2 & MRI CGCM2.3.2 \\
\hline A2 & & & & & \\
$2046-2064$ & 1.9 & 3.4 & 2.25 & 2.45 & 1.65 & 3.15 \\
$2080-2100$ & 5.2 & 5.5 & 5 & 5.2 & 4.3 & 4.8 \\
A1B & & & & & \\
$2046-2064$ & 1.5 & 2.5 & 1.6 & 2.7 & 1.3 & 2.25 \\
$2080-2100$ & 4.2 & 5 & 4 & 4.2 & 3.3 & 4.3 \\
B1 & & & & & & \\
$2046-2064$ & 1.5 & 2.7 & 1.2 & 0.9 & 1.1 & 3.5 \\
$2080-2100$ & 3.8 & 3.2 & 4 & 3.2 & 3 & \\
\hline
\end{tabular}

Table 4. GCM predicted changes in the mean annual precipitation of the future under A2, A1B and B1 scenarios.

\begin{tabular}{|c|c|c|c|c|c|c|}
\hline \multirow[b]{2}{*}{ Period } & \multicolumn{6}{|c|}{ GCM names predicting changes in mean annual precipitation (\%) } \\
\hline & CGCM3.1/T47 & CNRM-CM3 & GFDL-CM2.1 & PSLCM4 & MIROC3.2 & MRI CGCM2.3.2 \\
\hline \multicolumn{7}{|l|}{ A2 } \\
\hline 2046-2064 & -0.25 & -0.13 & -0.30 & -0.16 & -0.25 & 0.02 \\
\hline $2080-2100$ & -0.23 & -0.15 & -0.38 & -0.35 & -0.34 & 0.11 \\
\hline \multicolumn{7}{|l|}{ A1B } \\
\hline 2046-2064 & -0.05 & -0.08 & -0.32 & -0.15 & -0.06 & 0.02 \\
\hline $2080-2100$ & -0.18 & -0.18 & -0.30 & -0.21 & -0.17 & 0.06 \\
\hline \multicolumn{7}{|l|}{ B1 } \\
\hline 2046-2064 & -0.07 & -0.02 & -0.10 & -0.05 & -0.06 & 0.13 \\
\hline $2080-2100$ & -0.12 & -0.05 & -0.22 & -0.10 & -0.05 & 0.11 \\
\hline
\end{tabular}

(2080-2100) except MRI CGCM2.3.2. GFDL-CM2.1 yielded highest decreases. Figure 10 captures the anomaly maps of precipitation distribution (maps of percent deviation from historic data, 1980-2010) for A2, A1B and B1 scenarios for the periods 2046-2064 and 2080-2100 for the average change of multi-GCM ensemble. Under all emission scenarios, except B1 the basin will see decreases in precipitation at different rates. A2 emission scenario showed the highest decreases. The reductions in the lower and the west part of the basin would be quite large, as high as $34 \%$ and $30 \%$ for the half-centennial future and centennial future receptively under extreme A2 emission scenario. Under B1 scenario for the near future, $78 \%$ of the basin would experience an increase in precipitation as high as $10 \%$, while $22 \%$ of the basin located in the lower part would experience a reduction up to $30 \%$. However, for the far future, only $40 \%$ of the basin will see an increase up to $20 \%$ located in the upper part and the rest of the basin will see a decrease up to $30 \%$. 

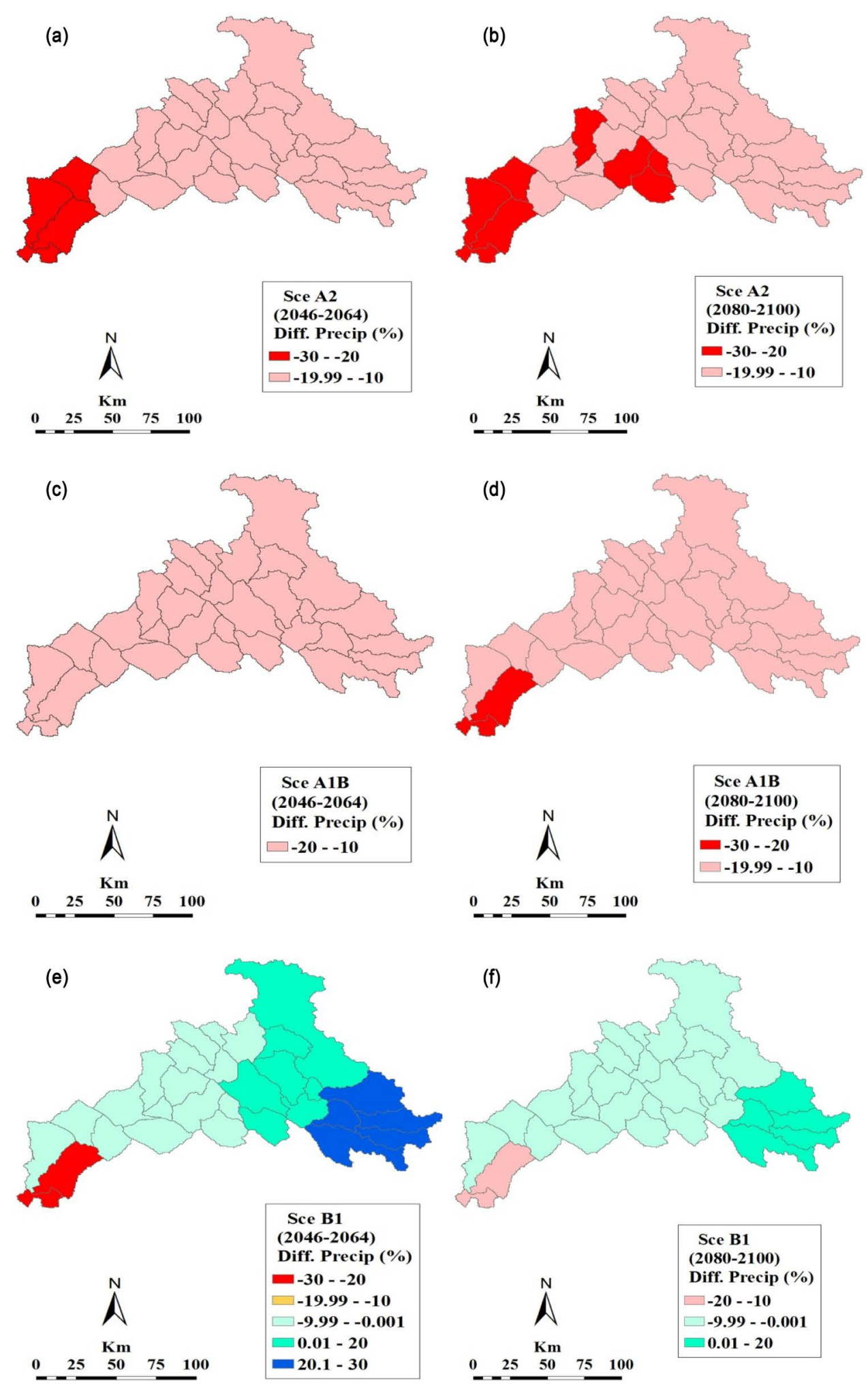

Figure 10. The impacts of climate change on the precipitation of the basin. (a) Anomaly based on scenario A2 for the period of 2046-2064; (b) Anomaly for A2 to 2080-2100; (c) Anomaly for A1B to 2046-2064; (d) Anomaly for A1B to 2080-2100; (e) Anomaly for B1 to 2046-264, and (f) Anomaly for B1 to 2080-2100. 


\subsection{The Impacts of Climate Change on Blue and Green Water under A2, A1B, B1 Emission Scenarios}

With the GCM projections incorporated in the SWAT model, it is evident that there would be decreases in blue water and green water storage at half-centennial and centennial projections in the future. The estimated values are provided in Table 5, where there is a consistent decrease except for MRI CGCM2.3.2 under A1B. GFDL gave the greatest reductions while MRI gave the lowest reductions. For A2 scenario, the GCMs projected decreases in blue water ranging from $15 \%$ to $43 \%$ in 2046 and from $26 \%$ to $53 \%$ in 2080 . Decreases in green water vary from $5 \%$ to $24 \%$ in 2064 and $10 \%$ to $31 \%$ in 2080. Under A1B scenario, the decrease of blue water ranging from $8 \%$ to $43 \%$ in 2046 and $33 \%$ to $53 \%$ in 2080 . The changes in blue water under B1 were between $8 \%$ and $23 \%$ in 2046 and between $9 \%$ and $33 \%$ in 2080 . The changes in green water were between $2 \%$ and $15 \%$ in 2046 and between $5 \%$ and $16 \%$ in 2080 .

Figure 11 shows the anomaly maps of blue water distribution (maps of percent deviation from historic data, 1982-2010) for A2, A1B and B1 scenarios for the periods 2046-2064 and 2080-2100 for the average change of multi-GCM ensemble. The half-centennial projection (2046-2064) shows a decrease in blue water under all emission scenarios for the whole basin except a small area located in the southeast of the basin which will experience an increase under B1 scenario for the both periods. A2 scenario project the highest reduction (38\%) followed by $\mathrm{A} 1 \mathrm{~B}(11 \%)$ and then $\mathrm{B} 1(6 \%)$. In the centennial future, the reduction will increase to $41 \%, 17 \%$ and $8 \%$ under $\mathrm{A} 2, \mathrm{~A} 1 \mathrm{~B}$ and B1, respectively. Similarly, green water flows will decrease under the three emission scenarios for the two future periods except B1 scenario for 2046 to 2064 period, where most of the basin would experience increases could reach to $5 \%$, which is captured in Figure 12.

Table 5. Annual changes in blue and green water flows in the future under A2, A1B and B1.

\begin{tabular}{|c|c|c|c|c|c|c|c|c|c|c|c|c|}
\hline \multirow[t]{3}{*}{ Periods } & \multicolumn{12}{|c|}{ Mean annual change in blue and green water (\%) } \\
\hline & \multicolumn{2}{|c|}{ CGCM3.1/T47 } & \multicolumn{2}{|c|}{ CNRM-CM3 } & \multicolumn{2}{|c|}{ GFDL- M2.1 } & \multicolumn{2}{|c|}{ IPSLCM4 } & \multicolumn{2}{|c|}{ MIROC3.2 } & \multicolumn{2}{|c|}{ MRI CGCM2.3.2 } \\
\hline & BLUE & GREEN & BLUE & GREEN & BLUE & GREEN & BLUE & GREEN & BLUE & GREEN & BLUE & GREEN \\
\hline \multicolumn{13}{|l|}{$\mathrm{A} 2$} \\
\hline 2046 & -0.31 & -0.21 & -0.17 & -0.11 & -0.43 & -0.21 & -0.31 & -0.24 & -0.17 & -0.12 & -0.15 & -0.05 \\
\hline 2080 & -0.37 & -0.21 & -0.32 & -0.10 & -0.52 & -0.31 & -0.53 & -0.24 & -0.30 & -0.21 & -0.26 & -0.10 \\
\hline \multicolumn{13}{|l|}{$\mathrm{A} 1 \mathrm{~B}$} \\
\hline 2046 & -0.16 & -0.12 & -0.16 & -0.10 & -0.42 & -0.23 & -0.43 & -0.17 & -0.30 & -0.21 & 0.08 & 0.10 \\
\hline 2080 & -0.37 & -0.21 & -0.33 & -0.10 & -0.52 & -0.32 & -0.53 & -0.24 & -0.43 & -0.40 & 0.26 & 0.02 \\
\hline \multicolumn{13}{|l|}{ B1 } \\
\hline 2046 & -0.09 & -0.02 & -0.14 & -0.05 & -0.08 & -0.06 & -0.08 & -0.15 & -0.11 & -0.14 & -0.23 & -0.02 \\
\hline 2080 & -0.09 & -0.10 & -0.07 & -0.05 & -0.33 & -0.14 & -0.16 & -0.10 & -0.11 & -0.07 & -0.13 & -0.05 \\
\hline
\end{tabular}



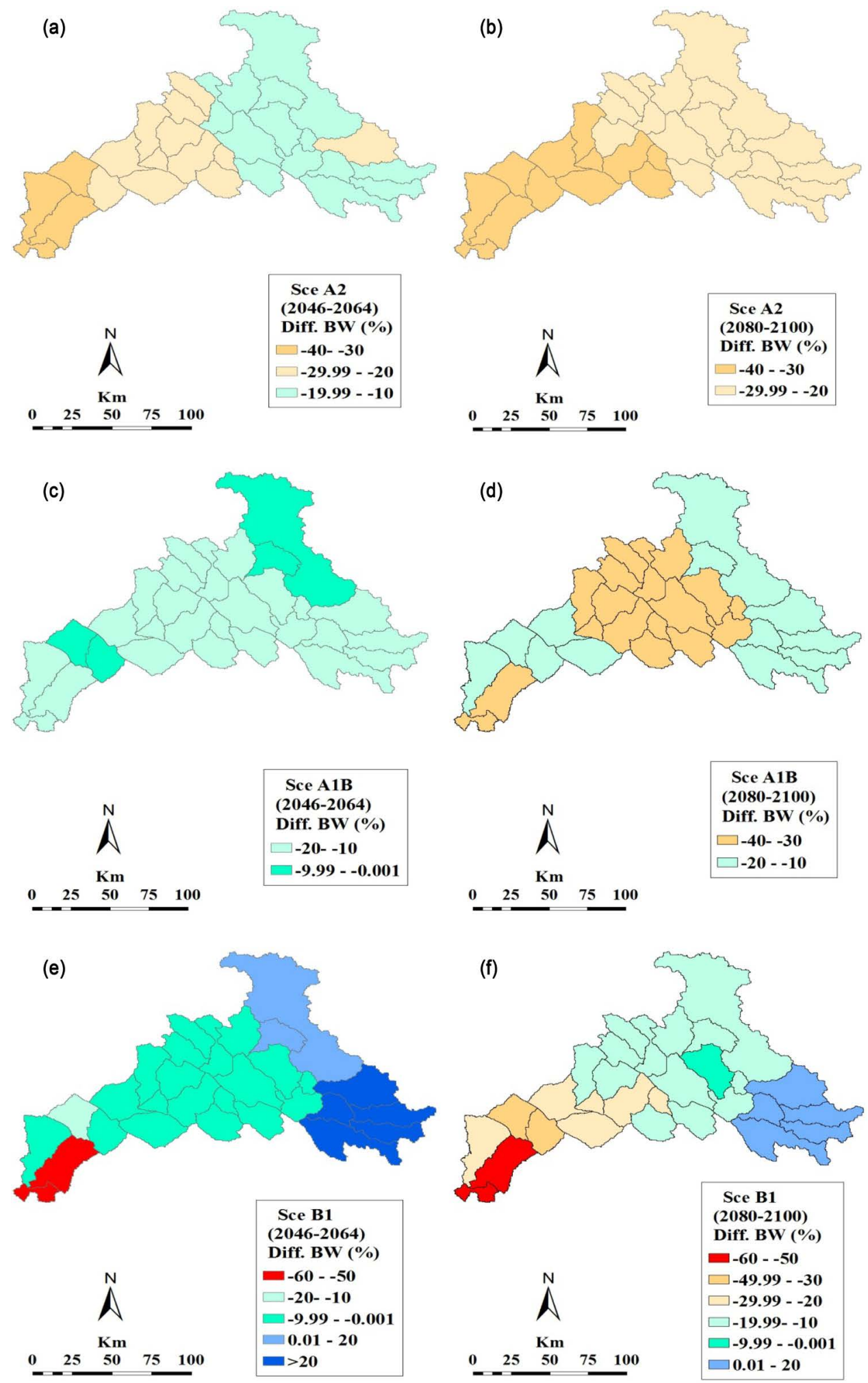

Figure 11. The impacts of climate change on the blue water of the basin. (a) Anomaly based on scenario A2 for the period of 2046-2064; (b) Anomaly for A2 to 2080-2100; (c) Anomaly for A1B to 2046-2064; (d) Anomaly for A1B to 2080-2100; (e) Anomaly for B1 to 2046-264; and (f) Anomaly for B1 to 2080-2100. 

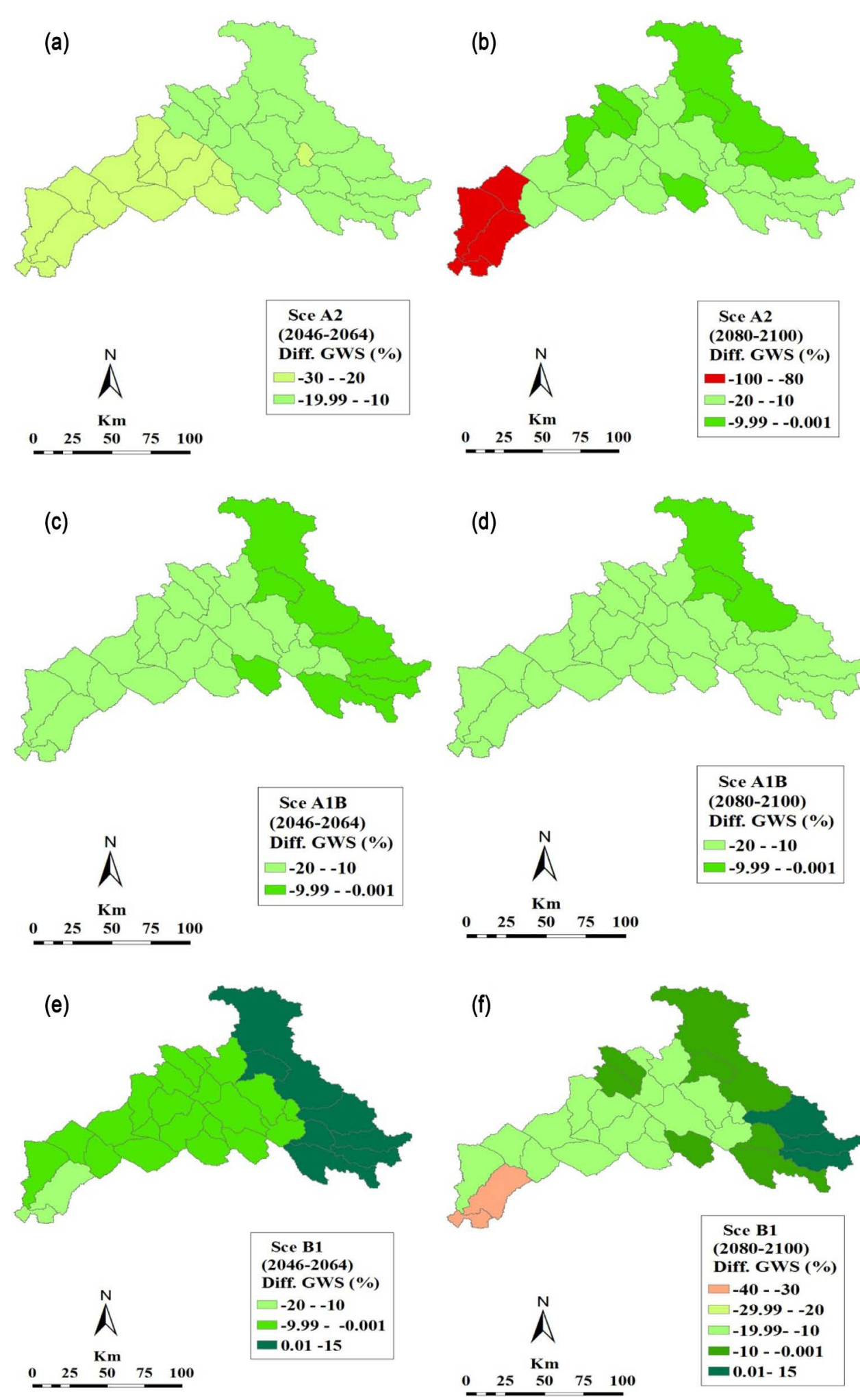

Figure 12. The impacts of climate change on the green water storage of the basin. (a) Anomaly based on scenario A2 for the period of 2046-2064; (b) Anomaly for A2 to 2080-2100; (c) Anomaly for A1B to 2046-2064; (d) Anomaly for A1B to 2080-2100; (e) Anomaly for B1 to 2046-264; and (f) Anomaly for B1 to 2080-2100. 

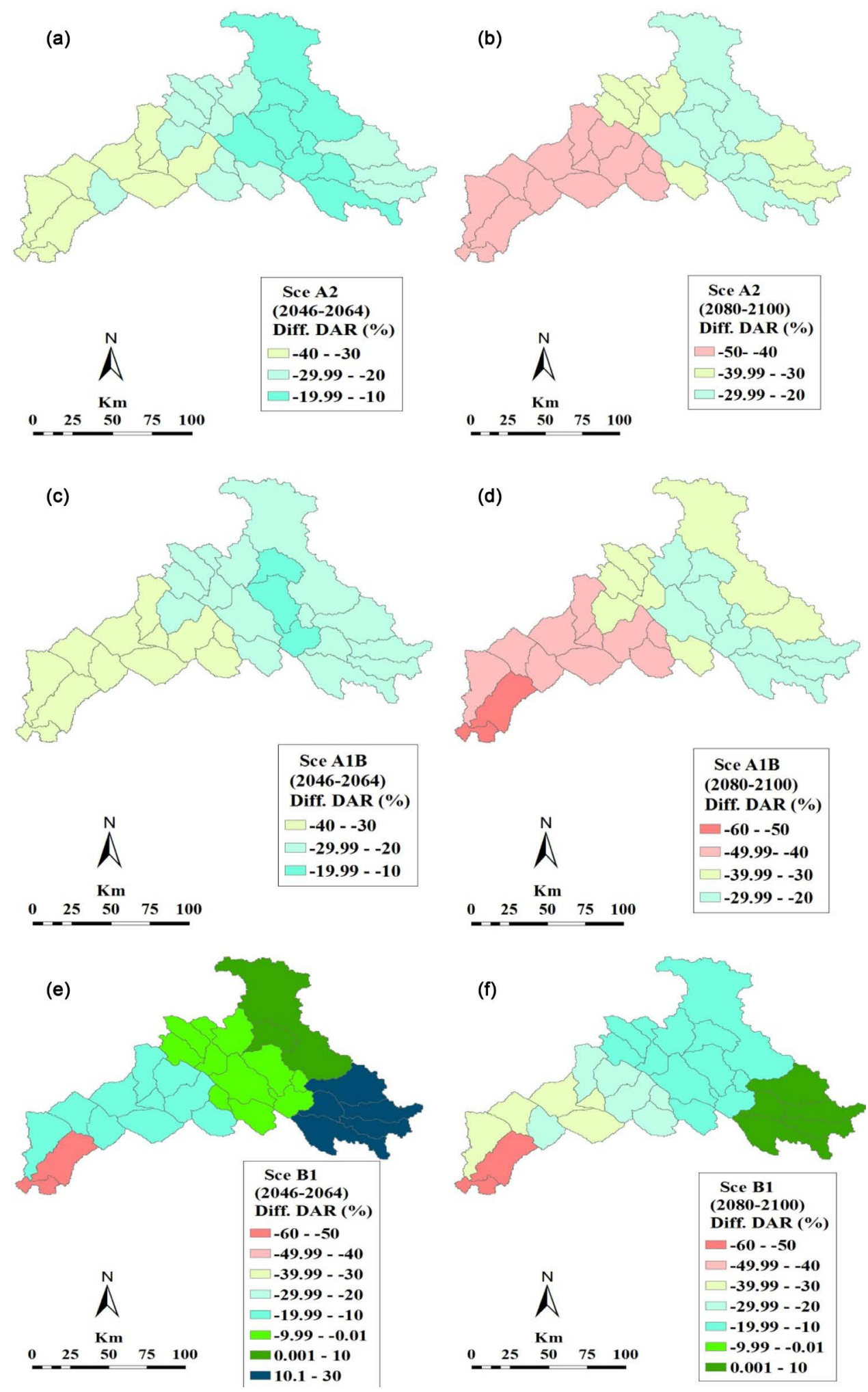

Figure 13. The impacts of climate change on the deep aquifer recharge of the basin. (a) Anomaly based on scenario A2 for the period of 2046-2064; (b) Anomaly for A1B to 2046-2064; (c) Anomaly for B1 to 2046-264; (d) Anomaly for A2 to 2080-2100; (e) Anomaly for A1B to 2080-2100, and (f) Anomaly for B1 to 2080-2100. 


\subsection{The Impacts of Climate Change on Deep Aquifer Recharge under A2, A1B, B1 Emission Scenarios}

All scenarios in the near and far future indicated that the entire basin will experience decreases could reach to 40 and $60 \%$ for the near future and far future, respectively under A2 scenarios. $60 \%-80 \%$ in ground water recharge (Figure 13). Under A1B, the highest decreases will be seen in south of the basin which will be up to 40 and $60 \%$ for the 2046 to 2064 and for 2080 to 2100 respectively. For B1 scenario, 20\% of the basin located in the south west will see decreases of up to $70 \%$ for the both periods. The central of the basin will experience increase of up to $20 \%$ in near future and up to $40 \%$ in far future. While $40 \%$ of the basin located in the north will experience an increases ranging from $10 \%$ to $30 \%$ in near future. In far future, only $10 \%$ of the basin located in the north east will see an increase up to $10 \%$. However, recharge might be overestimated because of assumption of consistency of land cover in the model.

\section{Conclusion}

In this study, the SWAT model was satisfactorily applied to estimate the blue and green water flows for the Lesser Zab basin. The results of calibration and validation of the SWAT model at two hydrological stations demonstrated that simulated data were in reasonable agreement with the measured data. The calibrated model was used to assess the impacts of climate change on blue and green water flows in the last three decades as well as identify blue water scarcity and green water storage availability in the basin. The spatial and temporal distributions of precipitation, blue and green water were presented. Generally, precipitation, blue and green water flow show a great reduction in the last three decades. These results can be attributed to global warming. Most of the basin suffers from water scarcity except small area located in the upper part of the region. The lower part of the basin shows high variability in green water storage availability. The impacts of projected climatic change on the water resources variability were assessed in the Lesser Zab Basin using the calibrated SWAT Model, CMIP3 and BCSD downscaling method. Projections of multi-GCMs indicated that temperature will increase while precipitation will decrease in the future. Blue water and green water flows are likely to decline in the future mainly because of an increase of air temperature and a decrease in precipitation.

\section{References}

[1] Keenan, T. and Cleugh, H. (2011) Climate Science Update: A Report to the 2011 Garnaut Review. Centre for Australian Weather and Climate Research, Canberra.

[2] Mimikou, M., Baltas, E. and Varanou, P. (2000) Regional Impacts of Climate Change on Water Resources Quantity and Quality Indicators. Journal of Hydrology, 234, 95-109. http://dx.doi.org/10.1016/S0022-1694(00)00244-4

[3] Coffey, R., Benham, B., Krometis, L.A., et al. (2014) Assessing the Effects of Climate Change on Waterborne Microorganisms: Implications for EU and US Water Policy. International Journal of Human and Ecological Risk Assessment, 20, 724-742. http://dx.doi.org/10.1080/10807039.2013.802583 
[4] Owor, M., Taylor, R., Tindimugaya, C. and Mwesigwa, D. (2009) Rainfall Intensity and Groundwater Recharge: Empirical Evidence from the Upper Nile Basin. Environmental Research Letters, 4, Article ID: 035009. http://dx.doi.org/10.1088/1748-9326/4/3/035009

[5] IPCC (2007) Climate Change 2007: Impacts, Adaptation and Vulnerability: Contribution of Working Group II to the Fourth Assessment Report of the Intergovernmental Panel on Climate Change. Cambridge University Press, Cambridge.

[6] Al-Ansari, N., Ali, A.A. and Knutsson, S. (2014) Present Conditions and Future Challenges of Water Resources Problems in Iraq. Journal of Water Resource and Protection, 6, 10661098. http://dx.doi.org/10.4236/jwarp.2014.612102

[7] Issa, I.E., Al-Ansari, N., Sherwany, G. and Knutsson, S. (2014) Expected Future of Water Resources within Tigris-Euphrates Rivers Basin, Iraq. Journal of Water Resource and Protection, 6, 421-432. http://dx.doi.org/10.4236/jwarp.2014.65042

[8] Talab, A.A. (2007) Evaluation of Some Irrigation Projects in Dukan Watershed as Controlling and Conservation of Water Resources. Iraqi Ministry of Water Resources, Center for the Study of Water Resources Projects for the Northern Region, Iraq. http://keu92.org/uploads/Search\%20engineering/Evaluation $\% 20$ of\%20some $\% 20$ irrigation $\%$ 20projects\%20in\%20Dukan.pdf

[9] Arnold, J.G., Srinivasan, R., Muttiah, R.S. and Williams, J.R. (1998) Large Area Hydrologic Modeling and Assessment Part I: Model Development. Wiley Online Library.

[10] Green, W.H. and Ampt, G. (1911) Studies on Soil Physics, 1. The Flow of Air and Water through Soils. Journal of Agriculture Science, 4, 1-24.

[11] Priestley, C. and Taylor, R. (1972) On the Assessment of Surface Heat Flux and Evaporation Using Large-Scale Parameters. Journal of American Meteroloigacal Society, 100, 81-92. http://dx.doi.org/10.1175/1520-0493(1972)100<0081:otaosh>2.3.co;2

[12] Hargreaves, G.L., Hargreaves, G.H. and Riley, J.P. (1985) Agricultural Benefits for Senegal River Basin. Journal of irrigation and Drainage Engineering, 111, 113-124. http://dx.doi.org/10.1061/(ASCE)0733-9437(1985)111:2(113)

[13] Food and Agriculture Organization (1995) The Digital Soil Map of the World and Derived Soil Properties, Version 3.5. Food and Agriculture Organization, Rome.

[14] Abbaspour, K.C., Yang, J., Maximov, I., Siber, R., Bogner, K., Mieleitner, J., Zobrist, J. and Srinivasan, R. (2007) Modelling Hydrology and Water Quality in the Pre-Alpine/Alpine Thur Watershed Using SWAT. Journal of Hydrology, 333, 413-430. http://dx.doi.org/10.1016/j.jhydrol.2006.09.014

[15] Nash, J. and Sutcliffe, J.V. (1970) River Flow Forecasting through Conceptual Models Part I-A Discussion of Principles. Journal of Hydrology, 10, 282-290. http://dx.doi.org/10.1016/0022-1694(70)90255-6

[16] Moriasi, D., Arnold, J., Van Liew, M., Bingner, R., Harmel, R. and Veith, T. (2007) Model Evaluation Guidelines for Systematic Quantification of Accuracy in Watershed Simulations. Soil \& Water Division of American Society of Agricultural and Biological Engineers, 50, 885-900.

[17] Maurer, E.P., Brekke, L., Pruitt, T., Thrasher, B., Long, J., Duffy, P., Dettinger, M., Cayan D. and Arnold, J. (2014) An Enhanced Archive Facilitating Climate Impacts and Adaptation Analysis. Bulletin of the American Meteorological Society, 95, 1011-1019. http://dx.doi.org/10.1175/BAMS-D-13-00126.1

[18] Cibin, R., Sudheer, K. and Chaubey, I. (2010) Sensitivity and Identifiability of Stream Flow Generation Parameters of the SWAT Model. Hydrological Processes, 24, 1133-1148. http://dx.doi.org/10.1002/hyp.7568 
[19] Li, Z., Xu, Z., Shao, Q. and Yang, J. (2009) Parameter Estimation and Uncertainty Analysis of SWAT Model in Upper Reaches of the Heihe River Basin. Hydrological Processes, 23, 2744-2753. http://dx.doi.org/10.1002/hyp.7371

[20] Falkenmark, M. and Rockström, J. (2006) The New Blue and Green Water Paradigm: Breaking New Ground for Water Resources Planning and Management. Journal of Water Resources Planning and Management, 132, 129-132. http://dx.doi.org/10.1061/(ASCE)0733-9496(2006)132:3(129)

[21] Falkenmark, M. (1989) The Massive Water Scarcity Now Threatening Africa: Why Isn't It Being Addressed? Ambio, 18, 112-118.

[22] Rijsberman, F.R. (2006) Water Scarcity: Fact or Fiction? Agricultural Water Management, 80, 5-22. http://dx.doi.org/10.1016/j.agwat.2005.07.001

[23] Zhang, X., Xu, Y.-P. and Fu, G. (2014) Uncertainties in SWAT Extreme Flow Simulation under Climate Change. Journal of Hydrology, 515, 205-222.

http://dx.doi.org/10.1016/j.jhydrol.2014.04.064

Submit or recommend next manuscript to SCIRP and we will provide best service for you:

Accepting pre-submission inquiries through Email, Facebook, LinkedIn, Twitter, etc. A wide selection of journals (inclusive of 9 subjects, more than 200 journals)

Providing 24-hour high-quality service

User-friendly online submission system

Fair and swift peer-review system

Efficient typesetting and proofreading procedure

Display of the result of downloads and visits, as well as the number of cited articles Maximum dissemination of your research work

Submit your manuscript at: http://papersubmission.scirp.org/

Or contact eng@scirp.org 